\title{
Is the BMA division really necessary?
}

\author{
NORMAN ELLIS
}

Since joining the BMA staff just over a year ago I have spoken at over 80 local meetings of doctors. No doubt the motives behind the invitations from divisions, regional councils, and local craft committees were varied. For some, the newly appointed senior industrial relations officer was being called upon to "explain himself," and for others a new face from BMA House probably filled a gap in last year's programme.

I had not been in BMA House long before I heard stories of eminent speakers who had traversed the country to address 10 members. Such dismal tales are not peculiar to the BMA. My experience has crossed the range of nine to 90 doctors. Undoubtedly the element of sociability, especially if refreshments are available, has attracted many members to these functions. But it's only fair to add that those meetings which left the strongest impression on me have often been attended by no more than a handful of doctors. The discussion at these poorly attended meetings was informal and frank, and usually turned on the question why so few members had bothered to come.

The BMA was born in the provinces as a reaction against the nineteenth century dominance of medicine by London doctors and so the division has played a vital part in the BMA's development. In many areas it still is doing so but it has nevertheless lost important traditional functions. Since the advent of postgraduate medical centres its previous role as a forum for scientific and learned activities has declined. In addition, the introduction of strengthened and autonomous craft committee structures has removed much medicopolitical activity from the division's purview.

\section{No new functions acquired}

But having lost these functions has the division acquired other spheres of activity, a new raison d'être for its continued existence? From my own brief experience the answer must be an unequivocal "No." Some divisions have managed to sustain an active social and medicopolitical calendar. Examples that I can name include Ormskirk, Rotherham, and Southend and, indeed, in these divisions some meetings are so popular that they are oversubscribed. Other divisions-and the Dukeries springs to mind-have developed a highly effective political role in relation to the local health authority and have become an active focus for local pressure group activity. For the most part these activities and thriving divisions are usually in localities with well-established community identities outside metropolitan areas which have also been well served by able and hard working honorary officers and committees.

Elsewhere the picture is mixed. There are some divisions which rarely meet and many others where the numbers attending

\footnotetext{
British Medical Association, BMA House, Tavistock Square, London WC1H 9JP

NORMAN ELLIS, MA, PHD, under secretary and senior industrial relations officer
}

meetings are remarkably low. This apathy and inactivity are most common in metropolitan areas, in part because doctors live well away from where they work, and a divisional structure where membership is still based primarily on a residential criterion has difficulty in establishing its relevance. Ironically some of the best attended meetings of these dormant divisions are those called for the specific purpose of winding up the division. Thus it appears that many members are firmly committed to keeping their divisions, albeit in abeyance, presumably for a rainy medicopolitical day. Perhaps doctors realise instinctively that if they faced a real crunch with the Government only the BMA has the necessary skill and facilities to rally a united profession. Be that as it may, the BMA cannot just rely upon cadres of committed and talented honorary officers to sustain the life of its divisions. Such doctors are busy and these rare talents are hard to find. In any case those who are willing to take on these responsibilities while they may be expected to serve for a long period of office are most unlikely to do so.

Should the BMA be concerned about the declining state of so many of its local units? Should it bother to resuscitate those moribund divisions? I see no merit in reviving a structure unless it has necessary functions to perform. Britain is littered with institutions that have long outlived their purpose, owing their survival to an inherent inertia. We must be wary of adding a further institution to this list. So if we wish the answer to these questions to be "Yes" the Association needs to be clear about the division's functions.

Like any other membership organisation, whether it be a professional body or trade union, the BMA surely needs some form of local structure. The reasons relate both to the environment in which the Association has to operate and also to internal organisational needs such as the procedures for determining policy and recruiting new members. The internal needs are more easily explained. Doctors do require a local forum in which all branches of the profession can meet on an informal basis for both social and medicopolitical purposes. In addition, the policymaking procedures of a large national body such as the BMA, with a widely dispersed membership, will always need to be firmly rooted in some kind of local structure.

\section{0 independent health services?}

It is fortuitous that the Government intends to delegate management responsibility to the district health authority in the reorganised NHS. Although it is not yet known how many health authorities will emerge from this exercise, informed estimates suggest that up to 160 new authorities may be appointed. Thus we could well be faced with numerous independent health services as each district authority evolves its own package of policies, and staff organisations (including the BMA) will need to equip themselves with the right structure to handle the problems that will ultimately emerge. The craft committees will undoubtedly continue to service their various branches of the profession at the local level in the newly de- 
veloped service, fulfilling functions analogous to those of the central craft committees. But the devolution of management responsibility to local health authorities will create a range of issues that transcend particular crafts and on which the whole profession will need to take a view.

Within a unified and centralised Health Service the BMA has been able to rely on a parallel centralised arrangement at BMA House for representing the whole profession. The division of responsibilities as between the BMA Council and the various central craft committees has been tailored to a centralised Health Service-a federal pattern that was confirmed by the Representative Body when it rejected Sir Paul Chambers's constitutional reforms in the early 'seventies. But in future the profession may well need to replicate that division of responsibility up to 160 times at local level if it is to continue to promote and protect the profession's interest in these new local authorities. As one division secretary observed, we will be looking for a local version of Dr John Havard to represent the profession in each of these local arenas.

To me the BMA division is the obvious machinery for formulating and presenting the profession's views. Indeed, if the divisional structure did not already exist the BMA would surely have to reinvent it - though I am convinced that the structure of divisions and their relation to BMA regional councils should be reviewed to ensure that the opinions of the crafts and of the training grades are properly represented. The influence that the profession will be able to exert on a health authority through this machinery on matters that affect all doctors practising within its district - for instance, decisions on the contraction or expansion of services-would depend more upon the tenacity and representative authority of the BMA division itself than on any formal requirement imposed on the authority to consult it. In short, the BMA's success locally will depend ultimately on the ability and persistence of its local advocates rather than simply on a statutory formula that gives the right of access to the authority.

I have been impressed on my visits by the hospitality and sociability of my divisional hosts. Certainly the social side of a division is important and local meetings should, and I'm sure always will, provide an informal and hospitable setting within which professional colleagues can meet to share their experiences, successes, frustrations, and golfing triumphs. I have also been struck by the way each division mirrors its particular locality: a not surprising observation, perhaps, since medical practice is largely rooted in the local community. Thus the instincts and reactions of doctors are noticeably different as between, for example, Brighton and Bromley. Encouragingly for the BMA, shared local problems and preoccupations often transcend the different branches of medicine. So the division is uniquely placed to serve the profession in its own locality. No amount of detailed attention and effort from head office can match the experience and knowledge of working doctors about local conditions and personalities. As responsibility for determining more and more aspects of health care is delegated to the local level, a highly devolved pattern of NHS management will evolve. This forthcoming change offers BMA divisions a not-tobe-missed opportunity to prove not only their worth but also their necessity.

\section{Life Offices' Association}

The BMA's Central Ethical Committee and the Life Offices' Association have reached agreement over some ethical matters related to life assurance. Statements of practice which have been agreed are:

\section{Confidentiality of medical reports}

(a) That administrative responsibilities are a matter for the chief executive of the life insurance company but that he must obtain the advice of the chief medical officer or other medical adviser in respect of the handling of medical information.

(b) That envelopes for the return of medical information from general practitioners should be marked "Confidential-Medical Report" and preaddressed to the chief medical officer or senior medical adviser at the head office or regional head office of the life insurance company. The envelopes should be routed for administrative convenience via local branch offices provided that they are not opened there.

\section{Wording of consent on proposal form}

That the wording of the form of consent to be given to a proposer to allow the insurance company to seek medical information be revised to read:

"I consent to the company seeking medical information from any doctor who at any time has attended me concerning anything which affects my physical or mental health or seeking information from any insurance office to which a proposal has been made for insurance on my life and I authorise the giving of such information."

The revised wording will be introduced as and when member offices reprint their proposal forms. It is anticipated that revision will be completed by October 1980. LOA members have been reminded that everything reasonably possible should be done to ensure that the proposer reads through the paragraph on consent before he signs the proposal form.

\section{Hospital and consultants' reports}

When seeking information from general practitioners LOA member companies will refrain from asking for specialists' reports in the first instance as a matter of routine. The

\section{BMA Notices}

\section{Trainees Subcommittee of the General Medical Services Committee}

Elections are to be held for representatives of doctors training for general practice in the following regions: 2 (Yorkshire), 4 (East Anglia), 7 (South-east Thames), 9 (Wessex), 10 (Oxford), 11 (South-western), 14 (Northwestern), and 17 (Northern Ireland).

Eligibility for nomination for election as a representative to the subcommittee is restricted to those in training either on a vocational training course, irrespective of whether they are in the hospital or general practice component, or as a trainee under the Trainee Practitioner Scheme.

Nominations are therefore invited for representatives for the above regions to serve on the subcommittee for the sessions 1980-1 to 1983-4. Nomination forms may be obtained reports are included within this category. assurance proposal. records relating to an individual. above regions and the regional advisers in general practice. companies are aware that $x$-ray and laboratory

The question of personal medical attendants' forms being used by insurance companies for employment purposes was raised in discussions and LOA member companies have now been asked to make clear in a covering letter to the general practitioner the purpose for which it is required and that it is not in respect of a life

Other matters on which discussions will continue are duration certificates and the separation of medical records from other

from the Secretary, British Medical Association, BMA House, Tavistock Square, London WC1H 9JP, and returned to the Secretary not later than Friday, 30 May 1980. Nominations must be proposed and seconded by two members of the electorate, which consists of those doctors in training, either on a vocational training course, irrespective of whether they are in the hospital or general practice component, or under the Trainee Practitioner Scheme. Nominations are also being sought from the local medical committees in the

J D J HAVARD Secretary 